\title{
Effectiveness of AD-MSCs injections for the treatment of knee osteoarthritis: Analysis of the current literature
}

\begin{abstract}
Vasiliadis $\mathrm{AV}^{1,2}$, Galanis $\mathrm{N}^{3}$
Abstract

Introduction: Knee osteoarthritis (OA) is a common pathology and is one of the leading causes of chronic disability among people aged over 65 years old. Currently, cell-based therapies involving intra-articular delivery of MSCs have emerged as a potential treatment solution.

Objective: The purpose was to examine the current literature regarding the clinical application of adipose-derived mesenchymal stem cells (AD-MSCs) for the management of knee OA.

Materials and methods: The electronic database, PubMed was searched from inception to May 31, 2019. This review included studies using cell population containing AD-MSCs for the treatment of knee OA. Data on clinical outcomes measured by various instrument such as VAS, WOMAC, KSS, KOOS, SF-36 were analysed, while MRI provided reliable and quantitative data on cartilage status throughout most compartments of the knee.

Results: A total of eight studies were included. Six studies used cultured AD-MSCs, while two studies used stromal vascular fraction. There were no significant adverse events related to the procedure, while the most of studies reported improvement from baseline in at least one outcome measure. The findings were not necessarily reflected in MRI evaluations nor were improvements always maintained after 2 years follow-up.

Conclusion: Our data suggest that the intra-articular injection of autologous AD-MSCs is a safe and effective therapeutic alternative for the treatment of severe knee OA patients and may have the potential to attenuate progression of the disease.
\end{abstract}

Key Words: Mesenchymal stem cells; Adipose tissue; Knee; Intra-articular injection; Osteoarthritis; Cartilage degeneration

\section{Introduction}

Osteoarthritis $(\mathrm{OA})$ is the most common degenerative joint disease of articular cartilage and a major cause of chronic pain and disability, affecting more than one-third of the population over 65 years-old ${ }^{[1,2]}$. Although, OA affects any joint in the body, large weight-bearing joints, especially the knee is the most common anatomical location ${ }^{[3]}$. The etiology of OA is multifactorial and includes aging, heredity, obesity, history of injury, and excessive exercise ${ }^{[4]}$. The diagnosis is based primarily on the patient's history and physical examination and is traditionally confirmed with radiographs that demonstrate asymmetric joint space narrowing, osteophyte formation, subchondral sclerosis and bony deformity ${ }^{[3,5]}$. Current treatment strategies for knee OA have focused on alleviating the pain and on improving function and quality of life and they usually range beyond oral nonsteroidal anti-inflammatory drugs, acetaminophen, patient education for early arthritis to braces, weight loss, physical therapy and intra-articular injections (hyaluronic acid, steroids, platelet-rich plasma $)^{[1,5]}$. Unfortunately, these treatments have little impact on the progression degeneration of articular cartilage.

In this context, modern treatments with regenerative medicine based on autologous mesenchymal stem cells (MSCs) show potential for cell-based articular cartilage repair in patients with knee $\mathrm{OA}^{[2,6]}$. MSCs can be obtained from multiple tissues and among these, bone marrow, adipose tissue and muscle derived MSCs are most commonly used, as they are easily obtained and abundantly available ${ }^{[7]}$. Adipose tissue represents an abundant and accessible source of adult stem cells with high potential for differentiation into mature cells, and hence they can form bone and cartilage $^{[3,7]}$. For these reasons, adipose-derived mesenchymal stem cells (AD-MSCs) seem to be promising therapeutic agents for clinical application in focal cartilage damage. In the current literature, the use of AD-MSCs in cartilage tissue engineering has received particular attention. For all the aforementioned reasons, the present review makes an effort to evaluate the efficacy of treatments containing AD-MSCs in knee OA without the combination of other techniques that could potentially cloud the data.

\section{Materials and methods}

\section{Search strategy}

Two authors independently searched one electronic database, the PubMed from inception to 31st May 2019, without language restriction, to identify articles related to clinical application of ADMSCs for knee osteoarthritis. Three sets of entry strings were combined with "and". The first set included alternative words for stem cells; the second set related to the anatomical region of interest

12nd Orthopaedic Department of "Papageorgiou" General Hospital, Ring Road-N.Eukarpia, 56403 Thessaloniki, Greece; ${ }^{2}$ Postdoctoral Researcher, School of Medicine, Aristotle University of Thessaloniki, University Campus, 54124 Thessaloniki, Greece; ${ }^{3} 1$ st Orthopaedic Department of "Papanikolaou" General Hospital, Aristotle University of Thessaloniki, 57010 Pilea-Hortiatis, Greece 
(i.e. the knee) and the third set included synonyms of osteoarthritis. Terms within each entry string were combined using "or" (Table 1).

\section{Selection criteria}

Titles of all identified records were screened for eligibility by the two independent raters. When inclusion was unable to be determined from the title, abstracts were then screened to check if they met the inclusion criteria. The full text of the articles was obtained to identify whether it can be included especially for those that authors remained uncertain about (Figure 1). All types of study design were eligible for inclusion, if they met the following criteria: (i) the study assessed the effect of intra-articular injection of AD-MSCs on human patients with knee OA; (ii) the study provided at least 6 months follow-up; (iii) the study reported outcomes using pain of function scores; (iv) the study was published in English language. Studies were excluded if they used: (i) MSC biologic adjuvants (scaffolds, platelet-rich plasma, fibrin glue, or hyaluronic acid; (ii) supplement treatments containing AD-MSCs with bone marrow stimulation techniques, subchondral drilling, abrasion, microfractures and arthroscopy debridement; (iii) reports on reviews, animal studies, in vitro studies, letters or replies.

\section{Limitations}

Firstly, our literature review, while rigorous, was limited to only one database (PubMed). Secondly, only articles published in English language were screened. In addition, we identified heterogeneity in the type of the included studies (randomized control trial, prospective and pilot studies), with some of them also including a small number of participants. Despite these limitations, the analysis conducted in the present review can safely provide an overall panorama of effectiveness of AD-MSCs injections for the treatment of knee OA.

Table 1. Search terms combinations

\begin{tabular}{|ccc|}
\hline Stem cell terms & Anatomical region term & Arthritis terms \\
\hline Stem cell, or & Knee & Osteoarthritis, or \\
Mesenchymal stem cell, or & & Cartilage degeneration \\
Mesenchymal stromal cell, or & & \\
MSC & & \\
\hline
\end{tabular}
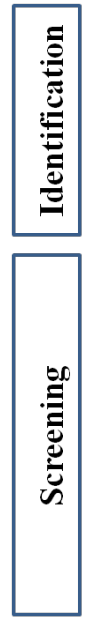

|

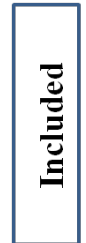

\section{Records identified through database searching (PubMed)} $(n=778)$

\begin{tabular}{|c|c|c|}
\hline & $\Downarrow$ & $\begin{array}{l}\text { Excluded }(\mathbf{n}=\mathbf{2 7 2}) \\
\text { - Reviews }(\mathrm{n}=131) \\
\text { - Animal studies }(\mathrm{n}=130) \\
\text { - Letter or reply }(\mathrm{n}=6) \\
\text { - Not English }(\mathrm{n}=5)\end{array}$ \\
\hline \multicolumn{2}{|c|}{ Titles screened $(n=506)$} & \\
\hline & $\downarrow$ & $\begin{array}{l}\text { Excluded }(\mathbf{n}=443) \\
\text { - Duplicates }(n=192) \\
\text { - Not relevant }(n=187) \\
\text { - Animal studies }(n=32) \\
\text { - Scaffolds }(n=12) \\
\text { - Case reports/series }(n=10) \\
\text { - In vitro }(n=6) \\
\text { - Reviews }(n=4)\end{array}$ \\
\hline \multicolumn{2}{|c|}{$\begin{array}{l}\text { Abstracts assessed for eligibility } \\
\qquad(n=63)\end{array}$} & \\
\hline & & $\begin{array}{l}\text { Excluded }(\mathbf{n}=\mathbf{2 5}) \\
\text { - Not relevant }(\mathrm{n}=20) \\
\text { - Animal studies }(\mathrm{n}=5)\end{array}$ \\
\hline \multicolumn{2}{|c|}{$\begin{array}{c}\text { Full text articles assessed for } \\
\text { eligibility }(n=38)\end{array}$} & Excluded $(n=34)$ \\
\hline & $\downarrow$ & $\begin{array}{l}\text { Blood MSCs }(n=26) \\
\text { - Used MSC including PRP, } \\
\text { HA, scaffold, fibrin glue, } \\
\text { or/and arthroscopy }(n=8)\end{array}$ \\
\hline Studies in & ed $(n=8)$ & \\
\hline
\end{tabular}

Figure 1. Study selection - Flow diagram 


\section{Results}

Design and characteristics of the included studies

The details of the eight articles included in the present review are reported in Table 2 . The grade of the osteoarthritis varied across studies and each used different scales to report: the K-L scale $\mathrm{e}^{[2,4,6,8}$ ${ }^{10]}$, and the IKDC ${ }^{[11]}$. Of those that used the K-L scale, lesions varied from grade I up to grade IV. Two studies were designed to include a control group, in which the participants did not receive the treatment, while they received conservative management consisting of simple analgesia, weight management and exercise ${ }^{[10]}$, and intra-articular injection of normal saline ${ }^{[11]}$.

Of the eight included studies, two studies used SVF assessing a total of 19 patients $^{[4,8]}$, and six studies used cultured AD-MSCs involving 96 patients $^{[2,6,9-12]}$. Of those studies that administered AD-MSCs, which require cell culture before intra-articular administration, the length of culture differed between the studies from one week [11] to three weeks ${ }^{[2,12]}$, while one study that administered multiple intraarticular knee injections cultured for three and then six weeks ${ }^{[9]}$. The resulting number of cells administered intra-articularly varied across studies ranging from 5 million cells ${ }^{[12]}$ to 100 million cells ${ }^{[10]}$. An intra-articular injection technique under visualization using ultrasound guidance was used in half of the studies ${ }^{[6,9-11]}$. The remaining four studies used an intra-articular injection without ultrasound guidance ${ }^{[2,4,8,12]}$. Four studies involving the knees of 60 patients harvested adipose tissue from the abdomen ${ }^{[2,10-12]}$, while two studies with 19 patients ${ }^{[4,8]}$ used tissue from the thigh, flanks and abdomen. Two studies of 36 patients did not report from where they obtained the adipose tissue ${ }^{[6,9]}$.

\section{Follow-up and outcome measures}

Total follow-up periods differed from six months ${ }^{[12]}$ to 24 months ${ }^{[2]}$. Four studies, involving 70 patients, were followed for only six months in total $[6,8,10,12]$. Six studies with 67 patients reported treatment effects on knee pain by using the visual analog scale (VAS) pain score (Table 2). The baseline VAS pain score in these studies were $67.8 \pm$ $7.5 \mathrm{~mm}$. The VAS pain score was significantly decreased to $29.9 \pm$ $11.7 \mathrm{~mm}$ at a mean follow-up period in these studies of $12 \pm 6.9$ months after the injection (Table 3). Eight studies with 133 patients reported treatment effects on self-reported physical function by using the Western Ontario and McMaster Universities Osteoarthritis Index (WOMAC) (Table 2). The baseline WOMAC score was $46.9 \pm 10.9$ with the score be reduced to $19.86 \pm 9.1$ after the injection, with a mean follow-up period of $12 \pm 7.3$ months (Table 3 ).

Six studies with 72 patients reported the treatment effect on cartilage volume and quality, evaluated using magnetic resonance imaging (MRI) (Table 2). The mean follow-up period of these studies was 16 \pm 6.6 months. In these analyses, two studies with similar clinical status of the patients reported an improvement of cartilage volume after an intra-articular injection of $\mathrm{AD}-\mathrm{MSCs}^{[2,9]}$. An increase in the thickness of the articular cartilage, despite the group of dose, with the volume of the cartilage of the bilateral knee persistently increased at six months after therapy ${ }^{[9]}$. A gradual regeneration of articular cartilage in the medial femoral and tibia condyles was demonstrated in MRI examination during the first 6 months, despite the dose escalation ${ }^{[12]}$. On the other hand, a recent randomized, placebo controlled clinical study did not find cartilage regeneration with no changes in the size of cartilage defect on MRI at six months after the AD-MSCs injection, whereas the cartilage defect was increased in the control group ${ }^{[11]}$. In only one study, no cartilage changes were observed at 3 months MRI evaluation. Authors were not surprised, as a post-MRI evaluation is being performed only three months after treatment ${ }^{[4]}$.
Adverse events

Of eight studies, four $(50 \%)$ reported adverse events related to intraarticular injection of AD-MSCs ${ }^{[6,8,11,12]}$. Only one study showed a severe adverse event ${ }^{[6]}$ namely unstable angina pectoris. Adverse events, related to the knee injection, included joint discomfort/effusion, knee pain/effusion, or edema. Owning to the large clinical and statistical heterogeneity among the studies, it was difficult to calculate the adverse event rates. In studies that reported timing of adverse event, knee pain/swelling occurred within 1 week after the injection ${ }^{[6,8]}$, while these symptoms were resolved spontaneously ${ }^{[6]}$ or with pain medication, such as acetaminophen ${ }^{[11]}$, and non-steroidal anti-inflammatory drugs ${ }^{[6]}$. Also, no serious adverse events were reported at the harvest site. The most common were discomfort and ecchymosis, which were resolved without further intervention ${ }^{[4,10]}$.

\section{Discussion}

The primary purpose of this study was to summarize the available literature data on evaluating the efficacy of intra-articular injections of AD-MSCs in knees with OA without the combination of other techniques. Data from this review suggest that the use of intraarticular autologous AD-MSCs in individuals with knee OA may provide satisfactory functional improvement and pain relief ${ }^{[11]}$, while it may have the potential to prevent disease progression ${ }^{[10]}$. However, two studies reported no observable changes in the cartilage in the MRI images between the pre-operative and 6-month evaluation ${ }^{[4,11]}$. This is not surprising as the MRI evaluation was performed early after the intra-articular injection. Thus, the MRI evaluation at least 612 months post-operative would be desirable and more reliable in order to assess the possible cartilage regeneration.

MSCs can be obtained from various tissues including bone marrow, adipose tissue, blood, and umbilical cord. Among these, bone marrow and adipose tissue are most commonly used ${ }^{[13]}$. Compared to other types of stem cells, AD-MSCs have various advantages. Firstly, they are easily accessible from subcutaneous liposuction from the belly or/and the hip/thigh region in large numbers ${ }^{[3,14]}$. Secondly, these cells demonstrate an enhanced in vitro proliferative capacity and therefore may produce the required numbers of cells for musculoskeletal tissue engineering and regenerative medicine applications ${ }^{[3]}$. Also, another advantage of AD-MSCs is that they have low risk of immune rejection ${ }^{[3]}$. Interestingly, in the present review all studies used autologous AD-MSCs, which were obtained with liposuction of the sub-abdominal adipose tissue. In two studies, additional AD-MSCs were obtained from autologous subcutaneous adipose tissue from the thigh, because of the low BMI of the patients enrolled in these studies ${ }^{[4,8]}$.

Generally, there are two ways of delivering AD-MSCs: i) cultured AD-MSCs, and ii) in stromal vascular fraction $(\mathrm{SVF})^{[15]}$. SVF from adipose tissue showed a mixed cell population of polygonal and fibroblastic cells, some containing a small proportion of MSCs and lipid droplets in their cytoplasm, whereas AD-MSCs displayed a spindle-shaped morphology and a very specific homogenous stem cells population ${ }^{[4,15]}$. While the current literature focused more on the use of AD-MSCs in patients with knee OA and showed satisfactory clinical and functional improvement, pain relief and structural regeneration of articular cartilage ${ }^{[2,9,11]}$; clinical studies on $\operatorname{SVF}^{[4,8]}$ demonstrated its chondroprotective, immunomodulatory, anti-fibrotic and anti-inflammatory properties ${ }^{[6]}$, suggesting a safe therapeutic approach for the treatment of severe knee OA.

According to our review, the relationship between MRI evaluations and clinical outcome measurements vary in their answer among patients with knee OA. 
Table 2. Summary of included studies

\begin{tabular}{|c|c|c|c|c|c|c|c|c|c|}
\hline Study & $\begin{array}{l}\text { ToS/ } \\
\text { LoE }\end{array}$ & $\begin{array}{l}\text { Population } \\
\text { (gender) }\end{array}$ & $\begin{array}{l}\text { Age, } \\
\text { mean }\end{array}$ & Grade OA & $\begin{array}{l}\text { Stem cell } \\
\text { type }\end{array}$ & Harvest site & $\begin{array}{l}\text { Delivery } \\
\text { method }\end{array}$ & Outcomes & $\begin{array}{l}\text { F/U } \\
\text { (month } \\
\text { s) }\end{array}$ \\
\hline $\begin{array}{l}\text { Lee et al., } \\
2019\end{array}$ & $\mathrm{RCT}$ & $\begin{array}{l}\text { I: } 12(3 \mathrm{M}, 9 \mathrm{~F}) \\
\text { C: } 12(3 \mathrm{M}, 9 \mathrm{~F})\end{array}$ & $\begin{array}{l}\text { I: } 62.2 \\
\text { C: } 63.2\end{array}$ & $\begin{array}{l}\text { I: II-III (K-L) } \\
\text { C: II-IV (K-L) }\end{array}$ & aAD-MSCs & Abdomen & $\begin{array}{l}\text { One intra- } \\
\text { articular } \\
\text { ultrasound- } \\
\text { guided } \\
\text { injection }\end{array}$ & $\begin{array}{l}\text { WOMAC, } \\
\text { VAS, } \\
\text { KOOS, } \\
\text { ROM, MRI } \\
\text { evaluation }\end{array}$ & 3,6 \\
\hline $\begin{array}{l}\text { Freitag et al., } \\
2019\end{array}$ & $\mathrm{RCT}$ & $\begin{array}{l}\text { Ia: } 10(7 \mathrm{M}, 3 \mathrm{~F}) \\
\text { Ib: } 10(4 \mathrm{M}, 6 \mathrm{~F}) \\
\text { C: } 10(5 \mathrm{M}, 5 \mathrm{~F})\end{array}$ & $\begin{array}{l}\text { Ia: } 54.6 \\
\text { Ib: } 54.7 \\
\text { C: } 51.5\end{array}$ & $\begin{array}{l}\text { I: II-III (K-L) } \\
\text { C: II-III (K-L) }\end{array}$ & aAD-MSCs & Abdomen & $\begin{array}{l}\text { One or two } \\
\text { intra-articular } \\
\text { ultrasound- } \\
\text { guided } \\
\text { injection }\end{array}$ & $\begin{array}{l}\text { NPRS, } \\
\text { KOOS, } \\
\text { WOMAC, } \\
\text { MOAKS }\end{array}$ & $\begin{array}{l}0,1,3 \\
6,12\end{array}$ \\
\hline $\begin{array}{l}\text { Song et al., } \\
2018\end{array}$ & $\mathrm{RCT}$ & $\begin{array}{l}\text { Ia: } 6(2 \mathrm{M}, 4 \mathrm{~F}) \\
\text { Ib: } 6(1 \mathrm{M}, 5 \mathrm{~F}) \\
\text { Ic: } 6(1 \mathrm{M}, 5 \mathrm{~F})\end{array}$ & $\begin{array}{l}\text { Ia: } 52.1 \\
\text { Ib: } 59.6 \\
\text { Ic: } 52.7\end{array}$ & $\begin{array}{l}\text { Ia: II-III (K-L) } \\
\text { Ib: II-III (K-L) } \\
\text { Ic: II-III (K-L) }\end{array}$ & aAD-MSCs & $\mathrm{n} / \mathrm{r}$ & $\begin{array}{l}\text { Three intra- } \\
\text { articular } \\
\text { ultrasound- } \\
\text { guided } \\
\text { injection }\end{array}$ & $\begin{array}{l}\text { WOMAC, } \\
\text { SF-36, NRS- } \\
11, \text { MRI } \\
\text { evaluation }\end{array}$ & $\begin{array}{l}3,6,12 \\
18,24\end{array}$ \\
\hline $\begin{array}{l}\text { Spasovski et } \\
\text { al., } 2018\end{array}$ & $\begin{array}{l}\mathrm{nRC} \\
\mathrm{T}\end{array}$ & I: $9(3 \mathrm{M}, 6 \mathrm{~F})$ & I: 63 & I: B, D (IKDC) & aAD-MSCs & Abdomen & $\begin{array}{l}\text { One intra- } \\
\text { articular } \\
\text { injection }\end{array}$ & $\begin{array}{l}\text { VAS, KSS, } \\
\text { HSS-KS, } \\
\text { TLS, ROM, } \\
\text { MRI } \\
\text { evaluation }\end{array}$ & $\begin{array}{l}3,6,12 \\
18\end{array}$ \\
\hline $\begin{array}{l}\text { Yokota et al., } \\
2017\end{array}$ & PS & $\mathrm{I}: 13(2 \mathrm{M}, 11 \mathrm{~F})$ & I: 74.5 & I: III-IV (K-L) & SVF & $\begin{array}{l}\text { Abdomen, or } \\
\text { inside thigh }\end{array}$ & $\begin{array}{l}\text { One intra- } \\
\text { articular } \\
\text { injection }\end{array}$ & $\begin{array}{l}\text { WOMAC, } \\
\text { VAS, } \\
\text { JKOM, BS- } \\
\text { POP }\end{array}$ & 1,6 \\
\hline $\begin{array}{l}\text { Jo et al., } \\
2017\end{array}$ & $\mathrm{CS} / 3$ & $\begin{array}{l}\text { Ia: } 3 \\
\text { Ib: } 3 \\
\text { Ic: } 3\end{array}$ & Ia-c: 61.8 & Ia-c: III-IV (K-L) & aAD-MSCs & Abdomen & $\begin{array}{l}\text { One intra- } \\
\text { articular } \\
\text { injection }\end{array}$ & $\begin{array}{l}\text { WOMAC, } \\
\text { VAS, KSS, } \\
\text { KOOS, MRI } \\
\text { evaluation }\end{array}$ & $\begin{array}{l}1,2,3 \\
6,12 \\
24\end{array}$ \\
\hline $\begin{array}{l}\text { Pers et al., } \\
2016\end{array}$ & PS & $\begin{array}{l}\text { Ia: } 6(3 \mathrm{M}, 3 \mathrm{~F}) \\
\text { Ib: } 6(3 \mathrm{M}, 3 \mathrm{~F}) \\
\text { Ic: } 6(2 \mathrm{M}, 4 \mathrm{~F})\end{array}$ & $\begin{array}{l}\text { Ia: } 63.2 \\
\text { Ib: } 65.5 \\
\text { Ic: } 65.2\end{array}$ & $\begin{array}{l}\text { Ia: III-IV (K-L) } \\
\text { Ib: III-IV (K-L) } \\
\text { Ic: IV (K-L) }\end{array}$ & aAD-MSCs & $\mathrm{n} / \mathrm{r}$ & $\begin{array}{l}\text { One intra- } \\
\text { articular } \\
\text { ultrasound- } \\
\text { guided } \\
\text { injection }\end{array}$ & $\begin{array}{l}\text { WOMAC, } \\
\text { VAS, PGA, } \\
\text { SAS, } \\
\text { KOOS, SF- } \\
36 \text {, MRI } \\
\text { evaluation }\end{array}$ & 3,6 \\
\hline $\begin{array}{l}\text { Fodor et al., } \\
2016\end{array}$ & $\mathrm{PS} / 4$ & I: $6(1 \mathrm{M}, 5 \mathrm{~F})$ & I: 59 & I: I-III (K-L) & SVF & $\begin{array}{l}\text { Abdomen, } \\
\text { flanks, or } \\
\text { lateral thighs }\end{array}$ & $\begin{array}{l}\text { One intra- } \\
\text { articular } \\
\text { injection }\end{array}$ & $\begin{array}{l}\text { WOMAC, } \\
\text { VAS, ROM, } \\
\text { TUG, MRI } \\
\text { evaluation }\end{array}$ & 3,12 \\
\hline
\end{tabular}


Table 3. Clinical outcomes according to pre-operative scores and post-operative scores, before and after cell injections, accompanying with rehabilitation procedure, and imaging evaluation of included studies

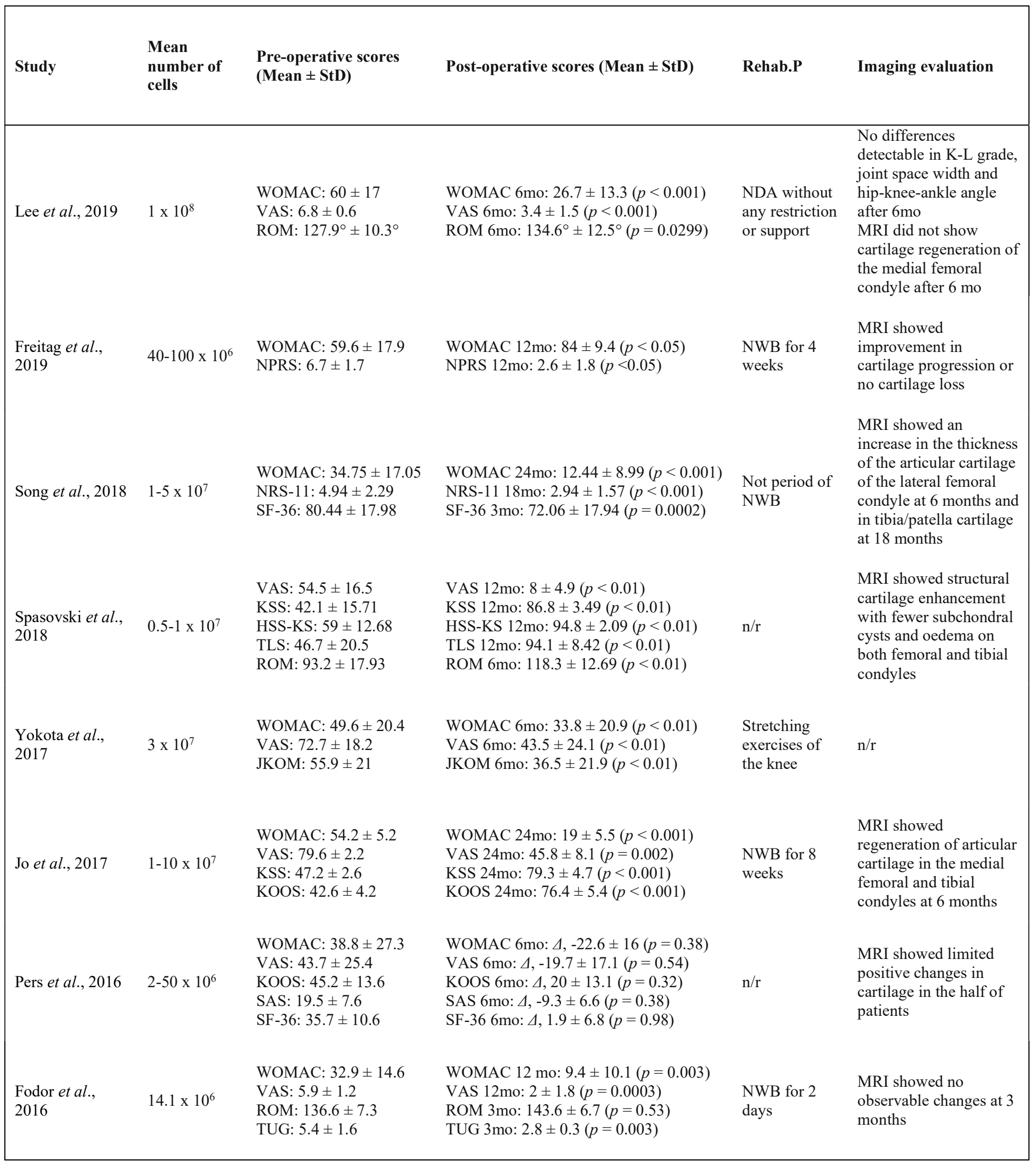


Spasovski et al., showed structural cartilage enhancement in accordance with observed clinical results on MRI 6 months after treatment (Table 3) ${ }^{[12]}$. In a cohort study from Seoul, the patients were divided into three groups according to the intra-articular dose escalation. This study revealed a relationship between regeneration of articular cartilage in the medial femoral/medial tibial condyles and pain/functional outcomes during the first 6 months, only for the highdose group. Signs of destruction of the regenerated cartilage were observed after 2 years for all the groups ${ }^{[2]}$. Also, the earlier study of Song et al., observed an increase in the thickness of the articular cartilage (high-dose group) on MRI, six months after the treatment, whereas clinical outcomes improved in this period (Table 3$)^{[9]}$.

In contrast, in both Fodor et al., and Lee et al., improvements in clinical outcomes (VAS, WOMAC, KOOS, ROM) were not correlated with MRI results ${ }^{[4,11]}$. Although, Lee et al., observed that the size of the cartilage defect at 6 months was significantly increased in the control group (intra-articular injection of normal saline) (Table 3$)^{[11]}$. Pers et al., found that their MRI results, specifically the dGEMRIC index, was not correlated with clinical changes (Table 3$)^{[6]}$. However, positive changes were only limited and suggested a possible cartilage improvement in only three of six patients. Thus, within this small number of patients, they did not observe any correlation between MRI and clinical outcomes ${ }^{[6]}$.

Furthermore, Song et al. ${ }^{[9]}$ investigated the dose effects of AD-MSC combined with repeated injections in cartilage volume. Their phase I/II clinical trials consisted of 18 patients suffering from knee OA who received injections of AD-MSCs. In phase I, patients were divided into 3 groups receiving either low-dose $\left(\begin{array}{llll}1 & \mathrm{x} & 10^{7}\end{array}\right)$, mid-dose $\left(2 \times 10^{7}\right)$ or high-dose $\left(5 \times 10^{7}\right)$ injections of MSCs. In the phase II, the third injection was provided at the discretion of patients. The MRI revealed an increase in cartilage volume to a higher degree after the third injection compared with that of the first two injections within the same interval from injection to follow-up time point. In addition, a study conducted on 30 symptomatic patients with knee $\mathrm{OA}$, divided into two treatment groups received intra-articular $\mathrm{AD}$ MSCs consisting of either a single or two injections, has revealed an improvement in cartilage or no progression in cartilage loss with stabilization of OA in $89 \%$ of patients in the two-injection group. By comparison, in one-injection group, $30 \%$ of the patients had further cartilage loss and $50 \%$ had progression of osteophyte formation ${ }^{[10]}$.

In the study of Song et al., it was revealed that AD-MSC therapy was associated with clinically significant improvement in pain and function in symptomatic knee $\mathrm{OA}^{[9]}$. No differences were found between the two treatment groups (one or two-injections), with twoinjections not showing any superiority on treatment ${ }^{[10]}$. In contrast, the SF-36 score demonstrated a tendency of reduction after the three inections during the whole follow-up, with the high-dose group exhibited more significant effects on pain relief and the improvement of knee function ${ }^{[9]}$. As a result, it is not clear whether two-injections can be more effective in the treatment of knee OA with AD-MSCs application.

This review included patients with different grade of knee OA according to Kellgren-Lawrence and IKDC classification systems. Most of the patients are classified with mild to moderate knee OA.
Thus, the observed effect of MSCs application on clinical outcome must not hold true in patients with severe knee OA. Freitag et al., conducted a study of patients with grade II and III knee OA using the Kellgren-Lawrence system and indicated that autologous AD-MSC therapy was a safe and effective treatment modality for moderate knee OA with the ability to modify disease progression ${ }^{[10]}$. According to this study, the same results were presented in a randomized clinical trial, where all the patients enrolled in this study were below grade $\mathrm{IV}^{[9]}$. Despite these two previous studies, Pers et al., reported clinical improvement with reduction in pain levels and WOMAC score, provided encouraging evidence of efficacy in patients with severe knee OA $(83 \%$ of patients were grade IV on the Kellgren-Lawrence system $)^{[6]}$.

Osteoarthritis is a classic age-related disorder that is usually symptomatic in people aged over 65 years old ${ }^{[5]}$. However, during the past 10 years, knee OA has doubled in people, less than 50 years of age ${ }^{[16]}$. There are several plausible reasons for this; the increase in life expectancy and sport activity of the general population, as well as the progressive nature of OA are some possible explanations ${ }^{[2]}$. In this review the included patients present a range of ages from 18 to 82 years old. Despite this wide range of ages, AD-MSCs application did not observed any related difference in pain and functional outcomes ${ }^{[6,10,12]}$. As result, these findings underline that age is not a possible factor to alter positive or negative the effect of AD-MSCs application in functional outcomes of patients with knee OA.

Overall, no severe adverse events or complications derived from the procedure (harvest site) or treatment (intra-articular injection) were noted during the follow-up period. Pain and swelling were the most common side effect at the injection or harvest site ${ }^{[4,6,8]}$, but in all cases, this resolved within a few days. Only one severe adverse event was reported in one patient, three months after injection, namely unstable angina pectoris, without positive cardiac markers and with a history of hypertension and hyperlipidemia ${ }^{[6]}$. More importantly the reported adverse events in our review from the included studies were mild and none resulted in death or the need to terminate the study. In general, direct intra-articular injection of AD-MSCs in the knee seems to be safe, simple and does not require a surgical procedure.

\section{Conclusion}

The treatment effectiveness of the intra-articular injections of ADMSCs seems to be clear in patients with mild to moderate knee OA, while more studies are needed in order to provide equivalent results in patients with severe knee OA. Interestingly, despite the wide range of patients' age, the present study showed no age effects on clinical outcomes of intra-articular AD-MSCs injections. Although the majority of studies were level of evidence 4 or 5 , the intra-articular injections of AD-MSCs seem to be favorable in improving knee pain, physical function and cartilage quality, without severe adverse events. However, these results are still contradictory and the evidence for these outcomes is not sufficient, because of the poor study design and large heterogeneity among populations. Future clinical studies should be focused on improving methodology for patient selection and include control groups. More studies with larger follow-up periods are mandatory to confirm such improvements in pain and function. 


\section{References}

1. Levy DM, Petersen KA, Scalley Vaught M, Christian DR, Cole BJ Injections for knee osteoarthritis: Corticosteroids, viscosupplementation, platelet-rich plasma, and autologous stem cells. Arthroscopy. 2018; 34(5):1730-43.

2. Jo HC, Chai JW, Jeong EC, Oh S, Shin JS, Shim H, Yoon KS. Intra-articular injection of mesenchymal stem cells for the treatment of osteoarthritis of the knee: A 2-year follow-up study. Am J Sports Med. 2017;45(12):2774-83.

3. Damia E, Chicharro D, Lopez S, Cuervo B, Rubio M, Sopena JJ, Vilar JM, Carrillo JM. Adipose-derived mesenchymal stem cells: Are they a good therapeutic strategy for osteoarthritis? Int $\mathrm{J}$ Molecul Sci. 2018;19(7):E1926

4. Fodor PB, Paulseth SG. Adipose derived stromal cell (ADSC) injections for pain management of osteoarthritis in the human knee joint. Aesthetic Surg J. 2016;36(2):229-36

5. Lespasio MJ, Piussi NS, Husni E, Muschler GF, Guarino AJ, Mont MA. Knee osteoarthritis: A primer. Perm J. 2017; 21:16-183.

6. Pers YM, Rackwitz, Ferreira R, Pullig O, Delfour C, Barry F, Sensebe L, Casteilla L, Fleury S, Bourin P, Noël D, Canovas F, Cyteval C, Lisignoli G, Schrauth J, Haddad D, Domergue S, Noeth $\mathrm{U}$, Jorgensen C, ADIPOA Consortium. Adipose mesenchymal stromal cell-based therapy for severe osteoarthritis of the knee: A phase I dose-escalation trial. Stem Cells Transl Med. 2016;5(7):847-56.

7. Roato I, Belisario DC, Compagno M, Lena A, Bistolfi A, Maccari L, Mussano F, Genova T, Godio L, Perale G, Formica M, Cambieri I, Castagnoli C, Robba T, Felli L, Ferracini R. Concentrated adipose tissue infusion for the treatment of knee osteoarthritis: clinical and histological observations. Int Orthop. 2019;43(1):15 23

8. Yokota N, Yamakawa M, Shirata T, Kimura T, Kaneshina H. Clinical results following intra-articular injection of adiposederived stromal vascular fraction cells in patients with osteoarthritis of the knee. Regen Ther. 2017; 6:108-12.

\section{Abbreviations}

$\begin{array}{ll}\text { ToS } & : \text { Type of Study } \\ \text { LoE } & \text { : Level of Evidence } \\ \text { OA } & : \text { Osteoarthritis } \\ \text { I } & : \text { Intervention } \\ \text { C } & : \text { Control } \\ \text { M } & : \text { Male } \\ \text { F } & : \text { Female } \\ \text { K-L } & : \text { Kellgren-Lawrence } \\ \text { RCT } & : \text { Randomized Controlled Trial } \\ \text { PS } & : \text { Prospective Study } \\ \text { CS } & : \text { Cohort Study } \\ \text { PL } & : \text { Pilot Study } \\ \text { aAD-MSCs } & : \text { Autologous Adipose-Derived Mesenchymal Stem Cells } \\ \text { SVF } & : \text { Stromal Vascular Fraction } \\ \text { WOMAC } & : \text { Western Ontario and McMaster Universities } \\ & \text { Osteoarthritis Index } \\ \text { VAS } & : \text { Visual Analog Scale } \\ \text { KOOS } & : \text { Knee Osteoarthritis Outcome Score } \\ \text { ROM } & : \text { Range of Motion } \\ \text { MRI } & : \text { Magnetic Resonance Imaging } \\ \text { NPRS } & : \text { Numeric Pain Rating Scale } \\ \text { MOAKS } & : \text { MRI Osteoarthritis Knee Scores }\end{array}$

$\begin{array}{ll}\text { PROMIS-29 } & : \text { Patient-Reported Outcomes Measurement } \\ \text { n/r } & : \text { Not reported } \\ \text { mo } & : \text { Months } \\ \text { StD } & : \text { Standard Deviation } \\ \text { NWB } & : \text { Non-Weight Bearing } \\ \text { Rehab.P } & : \text { Rehabilitation Procedure } \\ \text { NDA } & : \text { Normal Daily Activities } \\ \text { SF-36 } & : \text { Short form 36 Health Survey questionnaire } \\ \text { NRS-11 } & : \text { Numerical Pain Rating scale 11 } \\ \text { PGA } & : \text { Patient Global Assessment } \\ \text { SAS } & : \text { Short Arthritis Assessment Scale } \\ \text { TUG } & : \text { Timed Up-and-Go } \\ \text { JKOM } & : \text { Japanese Knee Osteoarthritis Measure } \\ \text { BS-POP } & : \text { Brief Scale for Psychiatric Problems in } \\ & \text { Orthopedic Patients } \\ \text { HSS-KS } & : \text { Hospital for Special Surgery Knee Score } \\ \text { KSS } & : \text { Knee Society Score } \\ \text { TLS } & : \text { Tegner-Lysholm Score } \\ \text { IKDC } & : \text { International Knee Documentation } \\ \text { F/U } & \text { Committee } \\ & : \text { Follow-Up }\end{array}$

\section{Potential Conflicts of Interests}

None

\section{Corresponding Author}

Angelo V. Vasiliadis, 2nd Orthopaedic Department of "Papageorgiou" General Hospital, Ring Road-N.Eukarpia, 56403 Thessaloniki, Greece. vasiliadis.av@gmail.com | vasiliadisvangelo@hotmail.com

9. Song Y, Du H, Dai C, Zhang L, Li S, Hunter DJ, Lu L, Bao C. Human adipose-derived mesenchymal stem cells for osteoarthritis: a pilot study with long-term follow-up and repeated injections. Regen Med. 2018;13(3):295-307.

10. Freitag J, Bates D, Wickham J, Shah K, Huguenin L, Tenen A Paterson K, Boyd R. Adipose-derived mesenchymal stem cell therapy in the treatment of knee osteoarthritis: a randomized controlled trial. Regen Med. 2019;14(3):213-30.

11. Lee WS, Kim HJ, Kim KI, Kim GB, Jin W. Intra-articular injection of autologous adipose tissue-derived mesenchymal stem cells for the treatment of knee osteoarthritis: A phase IIb, randomized, placebo-controlled clinical trial. Stem Cells Trans Med. 2019;8(6):504-11.

12. Spasovski D, Spasovski V, Baščarević Z, Stojiljković M, Vreća M, Anđelković M, Pavlović S. Intra-articular injection of autologous adipose-derived mesenchymal stem cells in the treatment of knee osteoarthritis. J Gene Med. 2018;20(1).

13. Maniar HH, Tawari AA, Suk M, Horwitz DS. The current role of stem cells in orthopaedic surgery. Malays Orthop J. 2015;9(3):1-7.

14. Usuelli FG, D’Ambrosi R, Maccario C, Indino C, Manzi L, Maffulli N. Adipose-derived stem cells in orthopaedic pathologies. Br Med Bull. 2017;124(1):31-54

15. Ranmuthu CDS, Ranmuthu CKI, Khan WS. Evaluating the curren literature on treatments containing adipose-derived stem cells for osteoarthritis: a progress update. Curr Rheumatol Rep. 2018;20(11):67.

16. Wallace JA, Worthington S, Felson DT, Jurmain RD, Wren KT, Maijanen H, Woods RJ, Lieberman DE. Knee osteoarthritis has doubled in prevalence since the mid-20th century. Proc Natl Acad Sci USA. 2017;114(35):9332-9336. 